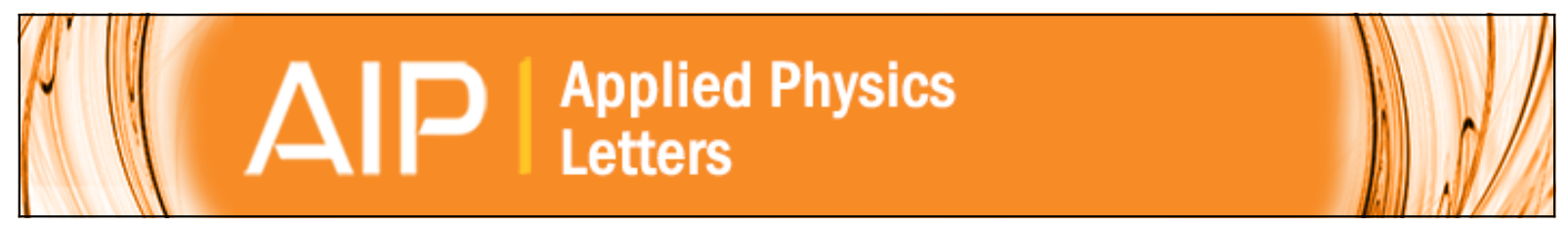

Effect of microstructural change on magnetic property of Mn-implanted p-type GaN

Jeong Min Baik, Ho Won Jang, Jong Kyu Kim, and Jong-Lam Lee

Citation: Applied Physics Letters 82, 583 (2003); doi: 10.1063/1.1541111

View online: http://dx.doi.org/10.1063/1.1541111

View Table of Contents: http://scitation.aip.org/content/aip/journal/apl/82/4?ver=pdfcov

Published by the AIP Publishing

Articles you may be interested in

Magnetic behavior of Mn-doped GaN (1 $\left.1^{-} 00\right)$ film from first-principles calculations

J. Appl. Phys. 111, 043907 (2012); 10.1063/1.3685901

Enhancement of magnetic properties by nitrogen implantation to Mn-implanted p-type GaN

Appl. Phys. Lett. 84, 1120 (2004); 10.1063/1.1647282

Effect of microstructural evolution on magnetic property of Mn-implanted p-type GaN

Appl. Phys. Lett. 83, 2632 (2003); 10.1063/1.1615676

Microstructural, optical, and magnetic properties of Mn-implanted p-type GaN

J. Appl. Phys. 93, 9024 (2003); 10.1063/1.1572974

Magnetic and structural properties of Mn-implanted $\mathrm{GaN}$

Appl. Phys. Lett. 78, 3475 (2001); 10.1063/1.1376659

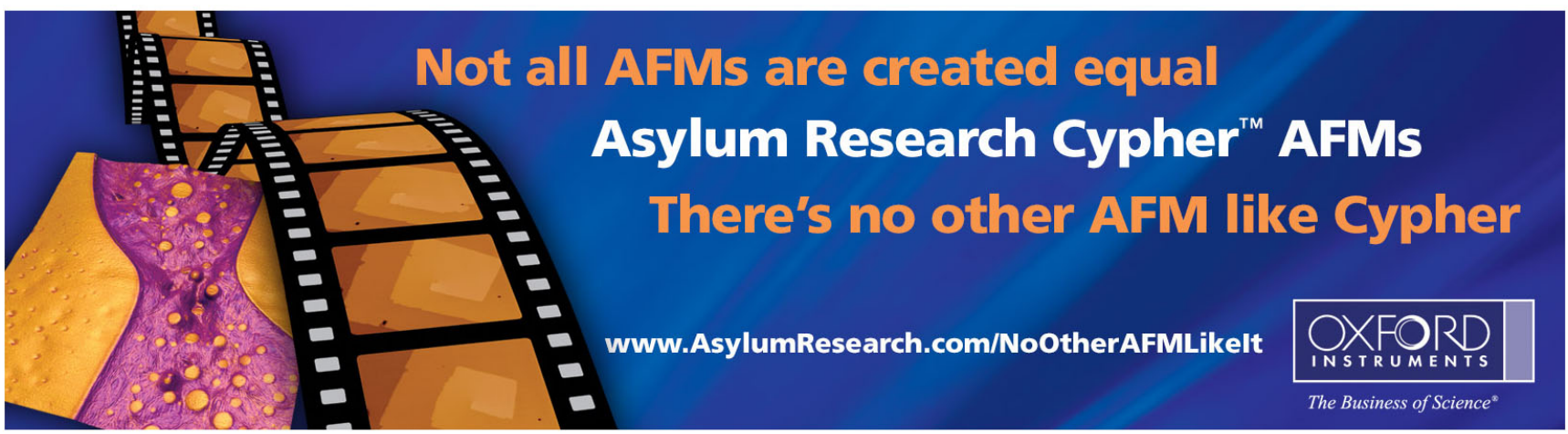




\title{
Effect of microstructural change on magnetic property of Mn-implanted p-type GaN
}

\author{
Jeong Min Baik, Ho Won Jang, Jong Kyu Kim, and Jong-Lam Lee ${ }^{\text {a) }}$ \\ Department of Materials Science and Engineering, Pohang University of Science and Technology \\ (POSTECH), Pohang, Kyungbuk 790-784, Korea
}

(Received 26 August 2002; accepted 9 December 2002)

\begin{abstract}
A dilute magnetic semiconductor was achieved by implanting $\mathrm{Mn}$ ions into $p$-type $\mathrm{GaN}$ and subsequent annealing. The ferromagnetic property was obtained after annealing at $800^{\circ} \mathrm{C}$. This was attributed to the formation of $\mathrm{Ga}-\mathrm{Mn}$ magnetic phases. Higher temperature annealing at $900^{\circ} \mathrm{C}$ reduced the ferromagnetic signal and produced antiferromagnetic $\mathrm{Mn}-\mathrm{N}$ compounds such as $\mathrm{Mn}_{6} \mathrm{~N}_{2.58}$ and $\mathrm{Mn}_{3} \mathrm{~N}_{2}$, leaving $\mathrm{N}$ vacancies. This provides evidence that $\mathrm{N}$ vacancies play a critical role in weakening the ferromagnetic property in the Mn-implanted GaN. (C) 2003 American Institute of Physics. [DOI: 10.1063/1.1541111]
\end{abstract}

Recently, dilute magnetic semiconductors (DMSs) based on III-V semiconductors have attracted a great deal of attention because of their application to magnetic semiconductor devices such as spin-field-effect transistors and spin-lightemitting diodes. ${ }^{1-3}$ In particular, $(\mathrm{Ga}, \mathrm{Mn}) \mathrm{N}$ is a very promising material because its Curie temperature is higher than room temperature according to the theoretical calculation. ${ }^{4}$ This allows the spintronic devices to operate at room temperature. Highly Mn-doped GaN film $\left(\geqslant 10^{21} / \mathrm{cm}^{3}\right)$ showing ferromagnetic behavior was successfully grown on sapphire (0001) by molecular-beam epitaxy (MBE). ${ }^{5}$ The ferromagnetic property was also reported in Mn-implanted GaN with subsquent annealing. ${ }^{6,7}$ Based on the material characterization using $\mathrm{x}$-ray diffraction (XRD) and/or transmission electron microscopy, it was proposed that $(\mathrm{Ga}, \mathrm{Mn}) \mathrm{N}$ solid solution and/or Ga-Mn binary phases could play a major role in emerging the ferromagnetic property in the Mn-doped GaN films. However, no clear evidence on the existence of such secondary phases has been experimentally provided because of the lack of experimental resolution. Meanwhile, x-ray scattering and photoemission spectroscopy using synchrotron radiation could provide quantitative information about the chemical and electronic properties, which should be crucial for the understanding of the origin of ferromagnetic properties in GaN-based DMS.

In this work, we studied microstructural evolution of Mn-implanted $p$-type GaN as a function of annealing temperature. Synchrotron XRD and synchrotron radiation photoemission spectroscopy (SRPES) were employed to identify secondary phases and chemical bonding states in the Mnimplanted and annealed $p$-type GaN. From these results, the effect of microstructural change on the magnetic property of Mn-implanted $p$-type $\mathrm{GaN}$ is discussed.

The GaN films used in this work were grown by metalorganic chemical deposition on a (0001) sapphire substrate. An undoped GaN layer with a thickness of $1 \mu \mathrm{m}$ was grown, followed by a growth of $1-\mu$ m-thick $p$-type $\mathrm{GaN}$ doped with $\mathrm{Mg}$. Electrical activation of the grown samples was carried out at $750^{\circ} \mathrm{C}$ for 4 min by rapid thermal annealing under an

${ }^{a)}$ Electronic mail: jllee@postech.ac.kr
$\mathrm{N}_{2}$ atmosphere. The net hole concentration in the film was determined to be $2.5 \times 10^{17} \mathrm{~cm}^{-3}$ by Hall measurements. After the growth of the films, $\mathrm{Mn}^{+}$ions were implanted into the $p$-type GaN films with an energy of $180 \mathrm{keV}$ and dose of $5 \times 10^{16} \mathrm{~cm}^{-2}$. All samples were held at $350{ }^{\circ} \mathrm{C}$ during the implantation to avoid amorphization. Subsequent annealing at 800 and $900{ }^{\circ} \mathrm{C}$ for $30 \mathrm{~s}$ was performed under flowing $\mathrm{N}_{2}$ gas in a face-to-face condition. The magnetization measurement was carried out using a superconducting quantum interference device magnetometer (MPMSXL, Quantum Design Co., Ltd).

Figure 1 shows magnetization curves at $10 \mathrm{~K}$ for samples annealed at 800 and $900^{\circ} \mathrm{C}$. The magnetization curves were obtained with the applied field parallel to the plane of the samples. The diamagnetic background of GaN substrate was subtracted. The hysteresis loops showed clear ferromagnetic behavior of the samples. It is clearly shown in Fig. 1 that the ferromagnetic signal for the $800{ }^{\circ} \mathrm{C}$-annealed sample was stronger than that for the $900^{\circ} \mathrm{C}$-annealed one. The coercive field increased from 40 to $79 \mathrm{Oe}$, while the residual magnetization decreased from $1.75 \times 10^{-3}$ to 7.75 $\times 10^{-4} \mathrm{emu} / \mathrm{g}$ with annealing temperature.

Figure 2 shows XRD profiles of Mn-implanted GaN

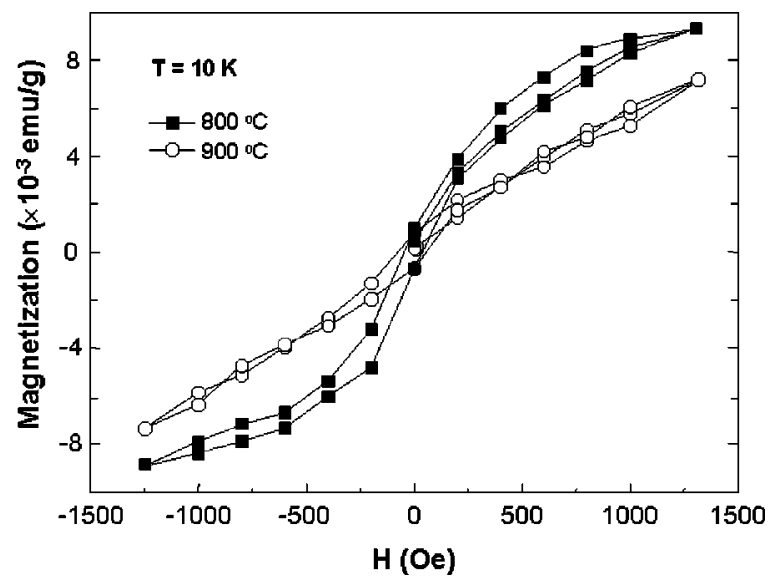

FIG. 1. Magnetization curves for Mn-implanted samples with annealing temperature. 


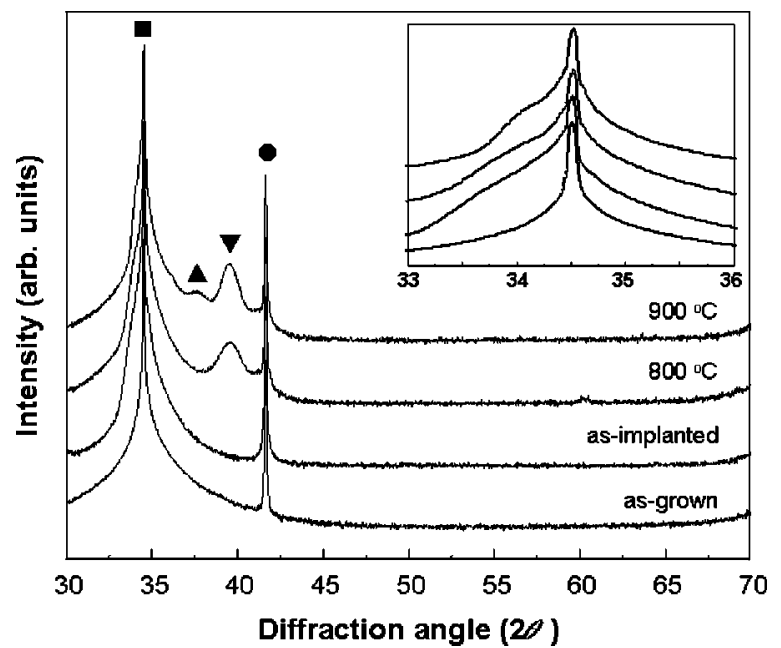

FIG. 2. Change of XRD scans of Mn-implantated GaN with annealing temperature. The inset shows the expanded view at around $\mathrm{GaN}$ (0002) peak;

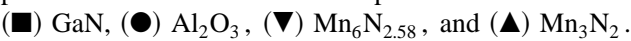

samples with annealing temperature. Compared to the asgrown sample, no reaction between $\mathrm{Mn}$ and $\mathrm{GaN}$ was observed in the as-implanted one. After annealing at $800^{\circ} \mathrm{C}$, a $\mathrm{Mn}-\mathrm{N}$ compound of $\mathrm{Mn}_{6} \mathrm{~N}_{2.58}$ was produced. When the sample was annealed at $900^{\circ} \mathrm{C}$, the $\mathrm{Mn}_{6} \mathrm{~N}_{2.58}$ peak intensity increased and a new peak corresponding to $\mathrm{Mn}_{3} \mathrm{~N}_{2}$ was observed. The inset in Fig. 2 shows enlarged XRD scans ranging from $2 \theta=33^{\circ}$ to $36^{\circ}$. A shoulder was found at the lower angle side of the $\mathrm{GaN}$ (0002) peak and its intensity became large at a higher annealing temperature. The shoulder could attribute to the strain along the $\mathrm{GaN} c$ axis, resulting from the decrease in implantation-induced damage during annealing. ${ }^{8}$

Figure 3 shows the change of the SRPES spectra of $\operatorname{Mn} 2 p_{3 / 2}$ and Ga $3 d$ core levels with annealing temperature. In order to remove surface oxides, the samples were in situ etched about $50 \AA$ using Ar ion sputtering. Only one peak was observed in the Mn 2 $p_{3 / 2}$ spectra for both as-implanted and $900^{\circ} \mathrm{C}$-annealed samples, as shown in Fig. 3(a). The peak corresponds to $\mathrm{Mn}-\mathrm{N}$ bond considering the XRD data in Fig. 2. In the sample annealed at $800^{\circ} \mathrm{C}$, a new peak locates at the lower binding energy by about $3.0 \mathrm{eV}$. This could be either metallic $\mathrm{Mn}-\mathrm{Mn}$ (Ref. 9) or $\mathrm{Ga}-\mathrm{Mn}$ bonds. The origin of the peak was revealed by the SRPES spectra of Ga $3 d$, shown in Fig. 3(b). The Ga $3 d$ spectrum of

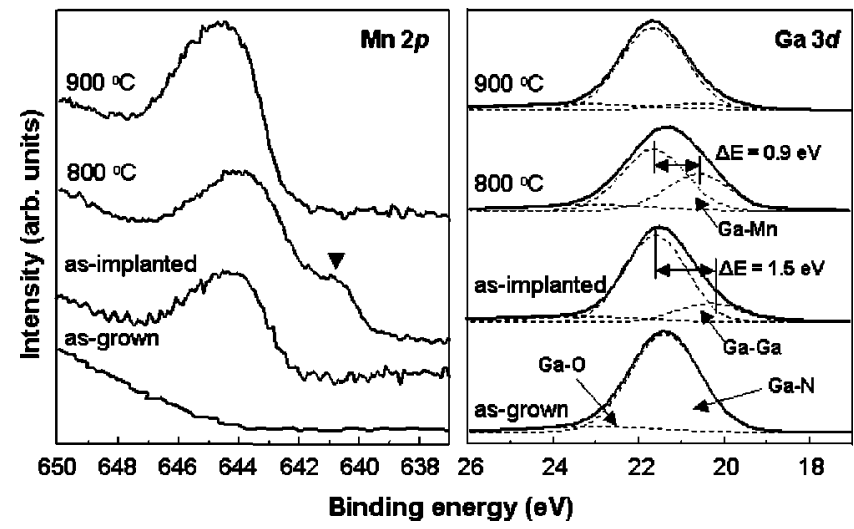

FIG 3 Change of the SRPES spectra for (a) $\mathrm{Mn} 2 p_{3 / 2}$ and (b) Ga $3 d$ core levels in Mn-implanted and annealed GaN.
TABLE I. Relative concentrations (\%) of chemical bonds determined from the Ga $3 d$ SRPES spectra in Fig. 3(b). The bracketed values represent the FWHM value of each bond.

\begin{tabular}{lcccc}
\hline \hline Sample & $\begin{array}{c}\mathrm{Ga}-\mathrm{N} \\
(1.52 \mathrm{eV})\end{array}$ & $\begin{array}{c}\mathrm{Ga}-\mathrm{O} \\
(2.71 \mathrm{eV})\end{array}$ & $\begin{array}{c}\mathrm{Ga}-\mathrm{Ga} \\
(1.42 \mathrm{eV})\end{array}$ & $\begin{array}{c}\mathrm{Ga}-\mathrm{Mn} \\
(1.50 \mathrm{eV})\end{array}$ \\
\hline As-grown & 91.2 & 8.8 & $\cdots$ & $\ldots$ \\
As-implanted & 81.9 & 10.1 & 8.0 & $\ldots$ \\
$800^{\circ} \mathrm{C}$ & 63.4 & 10.3 & $\cdots$ & 26.3 \\
$900^{\circ} \mathrm{C}$ & 80.9 & 13.0 & $\cdots$ & 6.1 \\
\hline \hline
\end{tabular}

the as-grown sample consists of $\mathrm{Ga}-\mathrm{N}$ and $\mathrm{Ga}-\mathrm{O}$ bonds. After the Mn implantation, the spectrum shows asymmetry at the lower bonding energy of the $\mathrm{Ga}-\mathrm{N}$ bond. The full width at half maximum (FWHM) value of Ga $3 d$ peak was measured to be $1.65 \mathrm{eV}$ for the as-grown $p$-type $\mathrm{GaN}$, but 1.95 $\mathrm{eV}$ for the $800^{\circ} \mathrm{C}$-annealed $p$-type GaN. This means that an additional bonding is superimposed in the Ga $3 d$ spectra. For the Mn-implanted sample, the superimposed peak could be attributed to metallic $\mathrm{Ga}$ atoms in $\mathrm{GaN}$ due to the implantation-induced loss of nitrogen atoms. ${ }^{10}$ The difference of binding energy between $\mathrm{Ga}-\mathrm{N}$ and $\mathrm{Ga}-\mathrm{Ga}$ bonds is in good agreement with the reported value of $1.7 \mathrm{eV} .{ }^{11}$ For the sample annealed at $800^{\circ} \mathrm{C}$, a new peak could be separated at the lower bonding energy by $0.9 \mathrm{eV}$ relative to the peak of $\mathrm{Ga}-\mathrm{N}$ bonds. The Ga atoms in the Mn-implanted sample could make bonding with $\mathrm{N}, \mathrm{O}$, and $\mathrm{Mn}$ atoms, such as $\mathrm{Ga}-\mathrm{N}, \mathrm{Ga}-\mathrm{O}$, and $\mathrm{Ga}-\mathrm{Mn}$ bonds, respectively. Considering the electron negativity of each element, the $\mathrm{Ga}-\mathrm{Mn}$ bond should be located between the $\mathrm{Ga}-\mathrm{N}$ and $\mathrm{Ga}-\mathrm{Ga}$ bonds. ${ }^{11}$ Therefore, the new peak in the $800^{\circ} \mathrm{C}$-annealed sample should originate from the $\mathrm{Ga}-\mathrm{Mn}$ bond. After annealing at $900^{\circ} \mathrm{C}$, the peak intensity for the $\mathrm{Ga}-\mathrm{Mn}$ bond decreased drastically. FWHM values and relative concentrations of deconvoluted peaks in the Ga $3 d$ spectra are summarized in Table I. Meanwhile, the relative atomic ratio of $\mathrm{Ga} / \mathrm{N}$ was determined from integrating intensities in the Ga $3 d$ and $\mathrm{N} 1 s$ spectra, summarized in Table II. The ratio measured at a detection angle $\theta=90^{\circ}$ in an asimplanted sample was set as 1.0 for reference. As the annealing temperature increases, the $\mathrm{Ga} / \mathrm{N}$ increases, meaning the production of $\mathrm{N}$ vacancies in the annealed $\mathrm{GaN}$. At a smaller $\theta$, the intensity of photoelectrons emitting from the surface becomes dominant due to the inelastic mean-free path of photoelectrons. At $\theta=30^{\circ}$, the increase in $\mathrm{Ga} / \mathrm{N}$ ratio with annealing temperature was more pronounced. This supports that nitrogen atoms were preferentially diffused out to the surface during annealing, leaving $\mathrm{N}$ vacancies near the surface region.

The change of surface band bending with annealing temperature was observed from valence band spectra, as shown in Fig. 4. The Fermi level was determined by linearly extrapolating the sloped region with the base line in the valence

TABLE II. Change of $\mathrm{Ga} / \mathrm{N}$ atomic ratio with the detection angle, $\theta$.

\begin{tabular}{cccc}
\hline \hline$\theta$ & As-implanted & $800{ }^{\circ} \mathrm{C}$ & $900{ }^{\circ} \mathrm{C}$ \\
\hline $90^{\circ}$ & 1 & 1.08 & 1.16 \\
$60^{\circ}$ & 1.08 & 1.41 & 1.53 \\
$30^{\circ}$ & 1.34 at: http: //scitalip.org/termscontins. Downloa 2.25 \\
\hline \hline
\end{tabular}




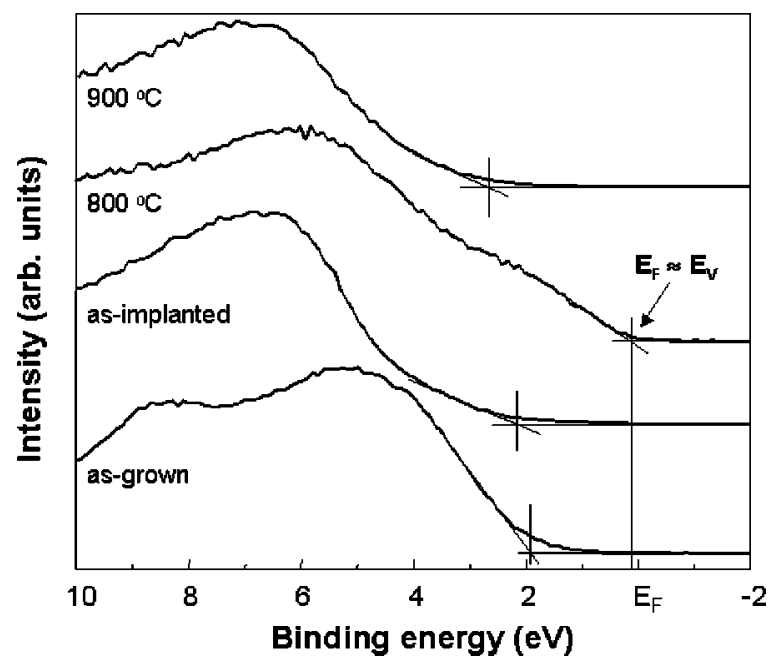

FIG. 4. Change of valence band spectra of Mn-implanted GaN with annealing temperature.

band spectrum of Au foil, defined as the level of zerobinding energy. For the sample annealed at $900^{\circ} \mathrm{C}$, the Fermi level shifts by $0.5 \mathrm{eV}$ toward conduction band in comparison with the as-implanted sample. This is related to $\mathrm{N}$ vacancies produced during annealing ${ }^{10}$ because $\mathrm{N}$ vacancies act as donors for electrons. ${ }^{12}$ However, after annealing at $800^{\circ} \mathrm{C}$, the Fermi level nearly coincides with the valence band maximum. This is due to the fact that the surface of the Mn-implanted sample changed into metallic surface, consistent with the observation of metallic $\mathrm{Ga}-\mathrm{Mn}$ bonds in Figs. 3(a) and 3(b).

The change of magnetic properties with annealing temperature could be explained in terms of the microstructural point of view, deduced from Figs. 3 and 4. At the higher annealing temperature at $900^{\circ} \mathrm{C}, \mathrm{Mn}-\mathrm{N}$ compounds, such as $\mathrm{Mn}_{3} \mathrm{~N}_{2}$ and $\mathrm{Mn}_{6} \mathrm{~N}_{2.58}$, were produced, leaving $\mathrm{N}$ vacancies behind. This was evidenced that the $\mathrm{Ga} / \mathrm{N}$ ratio at $\theta=90^{\circ}$ increased with annealing temperature (Table II). These $\mathrm{Mn}-\mathrm{N}$ compounds are known as antiferromagnetic materials with Neél temperature above $300 \mathrm{~K},{ }^{13,14}$ reducing the magnetic moment of the Mn-implanted GaN. In addition, N vacancies have shallow donor levels, located at about 30-40 meV below the conduction band edge. ${ }^{12}$ Thus, some part of the holes compensated with electrons generated from $\mathrm{N}$ vacancies led to the reduction of hole concentration. It was reported that the holes mediate the long-range interactions between the localized spins in the III-V magnetic semiconductors, enhancing the ferromagnetic properties of the materials. ${ }^{1}$ Therefore, the ferromagnetic signal reduced as the concentration of $\mathrm{N}$ vacancies increased.

It was shown that the ferromagnetic behavior found after annealing at $800{ }^{\circ} \mathrm{C}$ originated from the $\mathrm{Ga}-\mathrm{Mn}$ bond [Fig. 3 (a)] even though such phases were not identified from XRD measurements [Fig. 2]. It was reported that the ferromagnetic behavior of Mn-implanted GaN could be due to the formation of $\mathrm{Mn}_{3} \mathrm{Ga}$ phase. ${ }^{7}$ Thus, it is proposed that the $\mathrm{Ga}-\mathrm{Mn}$ bond could originate from a binary phase of $\mathrm{Ga}-\mathrm{Mn}$. No observation of such a $\mathrm{Ga}-\mathrm{Mn}$ phase might be attributed to the nanoscale size ${ }^{7}$ and the $\mathrm{Ga}-\mathrm{Mn}$ magnetic phases with random orientation. The $\mathrm{Ga}-\mathrm{Mn}$ magnetic phases disappeared as the annealing temperature increased to $900{ }^{\circ} \mathrm{C}$. This could be explained to result from the decrease in $\mathrm{Mn}$ concentration in $\mathrm{GaN}$ associated with the precipitation of $\mathrm{Mn}$ nitride. From this, it is suggested that optimum annealing temperature $\left(<900^{\circ} \mathrm{C}\right)$ could be an important parameter in enhancing the ferromagnetism in the Mn-implanted and annealed $\mathrm{GaN}$ by suppressing the production of $\mathrm{N}$ vacancies.

In conclusion, the $\mathrm{Ga}-\mathrm{Mn}$ magnetic phases contributing to the ferromagnetic property were produced after annealing Mn-implanted $p$-type $\mathrm{GaN}$ at $800^{\circ} \mathrm{C}$. The increase in the annealing temperature to $900{ }^{\circ} \mathrm{C}$ promoted the formation of antiferromagnetic $\mathrm{Mn}-\mathrm{N}$ compounds such as $\mathrm{Mn}_{6} \mathrm{~N}_{2.58}$ and $\mathrm{Mn}_{3} \mathrm{~N}_{2}$, leaving $\mathrm{N}$ vacancies near the surface region. The results suggest that the ferromagnetic property could be enhanced by an optimizing annealing temperature $\left(<900{ }^{\circ} \mathrm{C}\right)$ to avoid the predominant reaction of $\mathrm{Mn}$ atoms with $\mathrm{N}$.

The authors would like to thank M. S. Park for useful advice and technical support. This work was supported in part by Korea Science and Engineering Foundation through the Quantum-functional Semiconductor Research Center at Dongguk University in 2002, and in part by the project for "National Research Laboratory" sponsored by the Korea Institute of Science and Technology Evaluation and Planning (KISTEP). High-resolution XRD and SRPES using synchrotron radiation were carried out at the 3C2 and 8A1 SPEM beamlines at Pohang Accelerator Laboratory (PAL), respectively.

${ }^{1}$ H. Ohno, Science 281, 951 (1998).

${ }^{2}$ H. Ohno, A. Shen, F. Matsukura, A. Oiwa, A. Endo, S. Katsumoto, and Y. Iye, Appl. Phys. Lett. 69, 363 (1996).

${ }^{3}$ M. L. Reed, N. A. El-Masry, H. H. Stadelmaier, M. K. Ritums, M. J. Reed, C. A. Parker, J. C. Roberts, and S. M. Bedair, Appl. Phys. Lett. 79, 3473 (2001).

${ }^{4}$ T. Diel, H. Ohno, F. Matsukura, J. Cibert, and D. Ferrand, Science 287, 1019 (2000).

${ }^{5}$ S. Sonoda, S. Shimizu, T. Sasaki, Y. Yamamoto, and H. Hori, J. Cryst. Growth 237, 1358 (2002).

${ }^{6}$ Y. Shon, Y. H. Kwon, D. Y. Kim, X. Fan, D. Fu, and T. W. Kang, Jpn. J. Appl. Phys., Part 1 40, 5304 (2001).

${ }^{7}$ N. Theodoropoulou, A. F. Hebard, M. E. Overberg, C. R. Abernathy, S. J. Pearton, S. N. G. Chu, and R. G. Wilson, Appl. Phys. Lett. 78, 3475 (2001).

${ }^{8}$ B. J. Pong, C. J. Pan, Y. C. Teng, G. C. Chi, W.-H. Li, K. C. Lee, and C.-H. Lee, J. Appl. Phys. 83, 5992 (1998).

${ }^{9}$ I. Wu and A. Kahn, J. Vac. Sci. Technol. B 16, 2218 (1998).

${ }^{10}$ Y. Nakano and T. Kachi, Appl. Phys. Lett. 79, 1468 (2001).

${ }^{11}$ J. F. Mouler, W. F. Strickle, P. E. Sobol, and K. D. Bomben, Handbook of X-Ray Photoelectron Spectroscopy (Perkin-Elmer, Eden Prairie, MN, 1992).

${ }^{12}$ P. Boguslawski, E. L. Briggs, and J. Bernholc, Phys. Rev. B 51, 17255 (1995).

${ }^{13}$ H. Yang, H. Al-Brithen, E. Trifan, D. C. Ingram, and A. R. Smith, J. Appl. Phys. 91, 1053 (2002).

${ }^{14}$ M. N. Eddine and E. F. Bertaut, Solid State Commun. 23, 147 (1977). 